Article

\title{
Poly(ionic liquid)-Modified Metal Organic Framework for Carbon Dioxide Adsorption
}

\author{
Guangyuan Yang ${ }^{1,2}$, Jialin Yu ${ }^{2}$, Sanwen Peng ${ }^{1, *}$, Kuang Sheng ${ }^{1}$ and Haining Zhang ${ }^{2, *}$ (i) \\ 1 China Tobacco Hubei Industrial Cigarette Materials, LLC, Wuhan 430051, China; \\ yangguangyuan@whut.edu.cn (G.Y.); shengk@163.com (K.S.) \\ 2 State Key Laboratory of Advanced Technology for Materials Synthesis and Processing, Wuhan University of \\ Technology, Wuhan 430070, China; zhn4you@yahoo.com \\ * Correspondence: pengsanwen@126.com (S.P.); haining.zhang@whut.edu.cn (H.Z.)
}

Received: 22 December 2019; Accepted: 1 February 2020; Published: 7 February 2020

\begin{abstract}
The design and synthesis of solid sorbents for effective carbon dioxide adsorption are essential for practical applications regarding carbon emissions. Herein, we report the synthesis of composite materials consisting of amine-functionalized imidazolium-type poly(ionic liquid) (PIL) and metal organic frameworks (MOFs) through complexation of amino groups and metal ions. The carbon dioxide adsorption behavior of the synthesized composite materials was evaluated using the temperature-programmed desorption (TPD) technique. Benefiting from the large surface area of metal organic frameworks and high carbon dioxide diffusivity in ionic liquid moieties, the carbon dioxide adsorption capacity of the synthesized composite material reached $19.5 \mathrm{~cm}^{3} \cdot \mathrm{g}^{-1}$, which is much higher than that of pristine metal organic frameworks $\left(3.1 \mathrm{~cm}^{3} \cdot \mathrm{g}^{-1}\right)$ under carbon dioxide partial pressure of 0.2 bar at $25^{\circ} \mathrm{C}$. The results demonstrate that the combination of functionalized poly(ionic liquid) with metal organic frameworks can be a promising solid sorbent for carbon dioxide adsorption.
\end{abstract}

Keywords: metal organic framework; poly(ionic liquid); carbon dioxide; adsorption; imidazolium; temperature-programmed desorption

\section{Introduction}

The unavoidable emission of $\mathrm{CO}_{2}$ generated by anthropogenic activities is one of the major contributors to the greenhouse effect and the accordingly induced environmental problems, particularly climate change and global warming [1-3]. Development of effective $\mathrm{CO}_{2}$ cleansing technologies is thus of great importance. Moreover, $\mathrm{CO}_{2}$ is also an important $\mathrm{C} 1$-chemical feedstock in different industrial fields, including chemical engineering, agriculture, and biosystems [4,5]. Capture through adsorption and further conversion of $\mathrm{CO}_{2}$ have become an important direction adopted in both academic and industrial areas.

Adsorption of $\mathrm{CO}_{2}$ by alkaline amine-based solutions is a commercially available technique that is often applied due to its excellent adsorption capacity [6,7]. However, the high volatility and decomposition of the applied alkaline amine and the serious corrosion to scrubbers have limited the practical applications [8-10]. Thus, the development of solid sorbents with a reasonable adsorption capacity and stability has become a widely investigated research area [11]. Particularly, amine-functionalized porous materials with a large surface area have been extensively investigated, and literature results have revealed that these materials are promising solid sorbents for $\mathrm{CO}_{2}$ adsorption [12-20]. Of the solid porous materials applied for $\mathrm{CO}_{2}$ adsorption, metal organic frameworks (MOFs) have attracted great attention due to their large surface area and the easy process for surface modification as pioneered by Yaghi [21-28] and well described in recently published topic reviews $[29,30]$. Among the developed MOF materials, $\mathrm{Cu}_{3}(\mathrm{BTC})_{2}$ synthesized from $\mathrm{Cu}^{2+}$ and 
1,3,5-benzenetricarboxylic acid (BTC) displays a promising ability for $\mathrm{CO}_{2}$ adsorption due to the large number of unsaturated active sites generated during thermal treatment for interaction with $\mathrm{CO}_{2}$ molecules [31]. The resulting $\mathrm{CO}_{2}$ storage capacity reached about $207 \mathrm{~cm}^{3} \cdot \mathrm{g}^{-1}$ at $25.7 \mathrm{bar}$ [31]. In addition, the exposed copper sites make the modification of the formed MOF possible through complexation with electron-rich atoms [32].

It has been reported that imidazolium-type ionic liquids exhibit high efficiency for $\mathrm{CO}_{2}$ capture due to the high solubility of $\mathrm{CO}_{2}$ caused by the formation of imidazolium-carbonate salts [33-37]. However, the dramatically increased viscosity of the reaction system after $\mathrm{CO}_{2}$ adsorption leads to the difficulty of mass transport of $\mathrm{CO}_{2}$ and the subsequent treatment for recycling [38]. This has led researchers' interests to poly(ionic liquid) (PIL), which exhibits both the unique characteristics of ionic liquids and the physicochemical properties of polymers [39-41]. For example, Tang et al. reported that synthesized PIL showed an enhanced $\mathrm{CO}_{2}$ absorption capacity and fast adsorption/desorption rates compared to room-temperature ionic liquids [39].

Inspired by the advantages of MOFs and PIL on $\mathrm{CO}_{2}$ capture, amine-functionalized imidazolium-type PIL-modified $\mathrm{Cu}_{3}(\mathrm{BTC})_{2}$ materials were designed and synthesized through complexation of amino groups on PIL with the exposed active sites of copper ions after thermal treatment. The idea behind this conceptual design was to improve the $\mathrm{CO}_{2}$ adsorption through the interaction of $\mathrm{CO}_{2}$ molecules with copper ions and ionic liquid moieties in addition to the physisorption in micropores of MOFs, and the application of the temperature-programmed desorption (TPD) technique was to differentiate the physisorption and chemisorption of $\mathrm{CO}_{2}$ molecules. The $\mathrm{CO}_{2}$ adsorption behavior of the thus synthesized composite material was evaluated under relatively mild conditions with the $\mathrm{CO}_{2}$ partial pressure of 0.2 bar at $25^{\circ} \mathrm{C}$ by using the TPD technique. It is expected that the PIL-modified $\mathrm{Cu}_{3}(\mathrm{BTC})_{2}$ can exhibit an improved $\mathrm{CO}_{2}$ adsorption capacity compared with $\mathrm{Cu}_{3}(\mathrm{BTC})_{2}$ and pure PILs.

\section{Materials and Methods}

\subsection{Materials}

1-Vinylimidazole (1-VIm, purity of 99\%), 2-bromoethanamine hydrobromide (98\%), and 2,2-azobisisobutyronitrile (AIBN) were purchased from Alfa Aesar (MA, US). Prior to use, AIBN was recrystallized from methanol. Triethylamine (>99.5\%), copper (II) nitrate hydrate $(99 \%)$, and 1,3,5-benzenetricarboxylic acid (98\%) were received from Aladdin (Shanghai, China). Deionized water with resistivity of $18.2 \mathrm{M} \Omega \cdot \mathrm{cm}^{-1}$ was generated from an Ulupure-H ultrapure water generator (Ulup, China). Unless otherwise specified, all the other solvents and reagents were used as received. The $\mathrm{Cu}_{3}(\mathrm{BTC})_{2}$ was synthesized by following the literature [31].

\subsection{Synthesis of Monomeric Ionic Liquid (VIm-NH $2 \cdot \mathrm{HBr}$ )}

The monomeric ionic liquid was synthesized according to the literature with slight modification [42]. Briefly, in a two-neck flask, 1-VIm (9.41 g) was dissolved in absolute ethanol $(50 \mathrm{~mL})$. After refluxing under protection of argon atmosphere, 2-bromoethanamine hydrobromide ( $20.50 \mathrm{~g})$ was added to the above solution. The mixture was continuously refluxed for $24 \mathrm{~h}$ and the resulting white precipitation was separated by centrifugation, followed by extensive washing with ethanol. The product $(26.50 \mathrm{~g})$ was obtained after drying under vacuum at $120^{\circ} \mathrm{C}$ for $12 \mathrm{~h} .{ }^{1} \mathrm{H} \mathrm{NMR}\left(\mathrm{D}_{2} \mathrm{O}, 298 \mathrm{~K}, 300 \mathrm{MHz}, \mathrm{ppm}\right) \delta$ : $7.92(\mathrm{~s}, 1 \mathrm{H}, \mathrm{N}=\mathrm{CH}-\mathrm{N}), 7.65(\mathrm{~s}, 1 \mathrm{H}, \mathrm{N}-\mathrm{CH}=\mathrm{C}), 7.13(\mathrm{~s}, 1 \mathrm{H}, \mathrm{N}-\mathrm{CH}=\mathrm{C}), 5.84(\mathrm{dd}, 2 \mathrm{H},=\mathrm{CH} 2), 5.46(\mathrm{dd}$, $1 \mathrm{H},=\mathrm{CH}), 4.77\left(\mathrm{~s}\right.$, residue water in $\left.\mathrm{D}_{2} \mathrm{O}\right), 4.58(\mathrm{~d}, 1 \mathrm{H},=\mathrm{N}-\mathrm{CH}-), 3.53\left(\mathrm{t}, 2 \mathrm{H}, \mathrm{C}-\mathrm{CH}_{2}-\mathrm{N}\right)$. FTIR $(\mathrm{KBr}$ pallet, $\mathrm{cm}^{-1}$ ): 3320, 3240, 3095, 3067, 2912, 1628, 1564, 1517, 1488, 1381, 1255, 1210, 1123.

\subsection{Synthesis of Poly(ionic liquid) (PIL-NH $\mathrm{N}_{2}$}

To a mixed solvent of $N, N^{\prime}$-dimethylformamide $(25 \mathrm{~mL})$ and deionized water $(10 \mathrm{~mL})$, the synthesized VIm-NH2·HBr (3.98 g) and AIBN (4.0 mg) were added to form a homogenous 
solution. After removal of the dissolved oxygen in the solution by three freeze-thaw cycles, the solution was placed in a thermostat at $80^{\circ} \mathrm{C}$ for polymerization and the polymerization time was set to $2 \mathrm{~h}$. After polymerization, the resulting white precipitate was separated by centrifugation and was then dispersed in methanol $(10 \mathrm{~mL})$. Excessive triethylamine was added to the above dispersion to remove hydrobromide and the white solid was dissolved rapidly. The products were finally collected by precipitation after addition of ethyl acetate, followed by drying using a lyophilizer.

\subsection{Synthesis of PIL-NH$H_{2}$-Modified $\mathrm{Cu}_{3}(B T C)_{2}$ (Denoted as $\mathrm{Cu}_{3}(\mathrm{BTC})_{2}-\mathrm{PIL}-\mathrm{NH}_{2}$ )}

A $0.80 \mathrm{~g}$ amount of $\mathrm{Cu}_{3}(\mathrm{BTC})_{2}$ was placed in a tube furnace and activated at $250{ }^{\circ} \mathrm{C}$ for $2.5 \mathrm{~h}$, during which time the sample's color turned from blue to purple. The activated sample of $\mathrm{Cu}_{3}(\mathrm{BTC})_{2}$ was subsequently added to a solution of PIL-NHs $(2.0 \mathrm{~g})$ in methanol $(5.0 \mathrm{~mL})$ under protection of argon and the mixture was continuously stirred at room temperature for $24 \mathrm{~h}$ until the color of $\mathrm{Cu}_{3}(\mathrm{BTC})_{2}$ became blue. The final composite product $(0.91 \mathrm{~g})$ was obtained after centrifugation and extensive washing with methanol, followed by drying at $70^{\circ} \mathrm{C}$ under vacuum for $12 \mathrm{~h}$.

\subsection{Characterization}

${ }^{1} \mathrm{H}$ nuclear magnetic resonance $\left({ }^{1} \mathrm{H}\right.$ NMR, Mercury VX-300 spectrometer) was applied to determine the chemical structure of the synthesized monomer using tetramethylsilane as internal standard. Fourier-transform infrared (FTIR) spectra were recorded on a 60SXB spectrometer (Nicolet) in the range of $400-4000 \mathrm{~cm}^{-1}$ with a resolution of $4 \mathrm{~cm}^{-1}$ to qualitatively determine the synthesis of the corresponding products. Thermal stability of the samples was investigated by thermogravimetric analysis (TGA) and differential scan calorimetry (DSC) using an STA449F3 thermal analyzer (Netzsch) under a dynamic heating mode with ramp rate of $10{ }^{\circ} \mathrm{C}$ per minute in air over the temperature range of $30-1000{ }^{\circ} \mathrm{C}$. X-ray diffraction $(\mathrm{XRD})$ patterns were recorded from $5^{\circ}$ to $70^{\circ}$ to determine the crystal structure of $\mathrm{Cu}_{3}(\mathrm{BTC})_{2}$ and $\mathrm{Cu}_{3}(\mathrm{BTC})_{2}-\mathrm{PIL}-\mathrm{NH}_{2}$ using $\mathrm{Cu} \mathrm{K} \mathrm{K}_{\alpha}$ irradiation sources with wavelength of $1.54 \AA$. The surface area and the porous structure of the samples were determined by nitrogen adsorption-desorption isotherms on a Micromeritics ASAP 2020 instrument at $77 \mathrm{~K}$ in the relative pressure range of $10^{-8}$ to 0.998 . Prior to the measurements, samples were degassed at $120{ }^{\circ} \mathrm{C}$ for $6 \mathrm{~h}$. The Brunauer-Emmett-Teller (BET) model was applied to calculate specific surface area and the Barrett-Joyner-Halenda $(\mathrm{BJH})$ approach was taken to obtain the pore size distribution. X-ray photoelectron spectroscopy (XPS, VG Multilab2000X, Al K $\alpha$ irradiation source) was applied to determine the elemental composition near the surface of samples.

\section{6. $\mathrm{CO}_{2}$ Adsorption}

The $\mathrm{CO}_{2}$ adsorption behavior was performed on a TPD apparatus TP-5080 (Tianjin Xianquan, China) using helium as carrier gas. The typical procedure includes pre-adsorption of $\mathrm{CO}_{2}$ at desired temperature under $\mathrm{CO}_{2}$ partial pressure of $0.2 \mathrm{bar}$, followed by temperature-dependent desorption and finally complete desorption of the adsorbed $\mathrm{CO}_{2}$ molecules at $200{ }^{\circ} \mathrm{C}$. The detailed procedure was described elsewhere [43]. The adsorbed amount of $\mathrm{CO}_{2}$ was calculated from the detected TPD signals of thermal conductivity detector using the software from the supplier.

\section{Results}

The idea behind the design of the composite materials for $\mathrm{CO}_{2}$ adsorption was to take the advantages of the large surface area of MOF materials and the great $\mathrm{CO}_{2}$ adsorption capacity of amine-functionalized imidazolium-type poly(ionic liquid)s. Thus, the designed amine-functionalized poly(ionic liquid) (PIL- $\mathrm{NH}_{2}$ ) was first synthesized through simple free-radical polymerization, as illustrated in Figure 1a. The amino groups on the synthesized PIL-NH $\mathrm{N}_{2}$ can therefore interact with the exposed copper ions on the preformed metal organic framework through complexation, leading to the modification of $\mathrm{Cu}_{3}(\mathrm{BTC})_{2}$ by poly(ionic liquid), as shown in Figure $1 \mathrm{~b}$. 
(a)
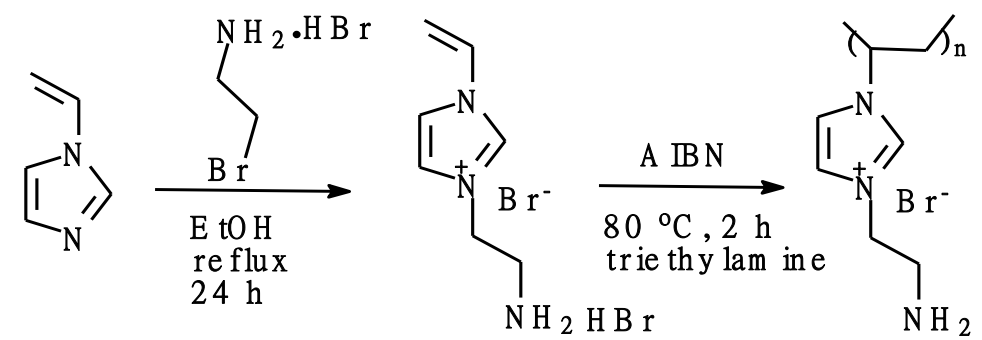

$1-\mathrm{V}$ Im

$\mathrm{V} \mathrm{Im}-\mathrm{N} \mathrm{H}_{2} \mathrm{H} \mathrm{B} \mathrm{r}$

$\mathrm{PIL}-\mathrm{NH}_{2}$

(b)

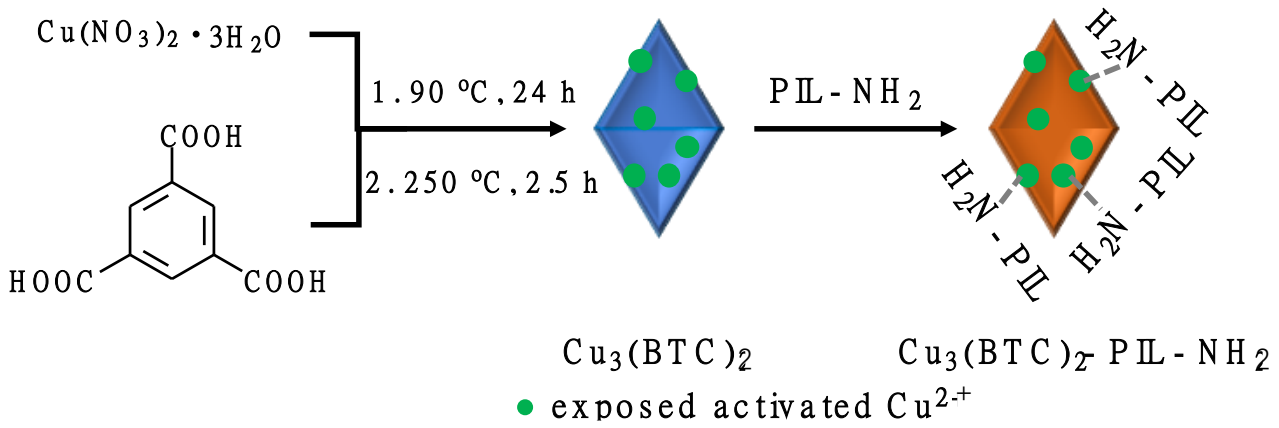

Figure 1. (a) Synthesis of amine-functionalized imidazolium-type poly(ionic liquid). (b) Schematic illustration of the synthetic process of composite sorbent of $\mathrm{Cu}_{3}(\mathrm{BTC})_{2}$ and poly(ionic liquid).

The FTIR spectrum was first recorded to monitor the interaction of $\mathrm{Cu}_{3}(\mathrm{BTC})_{2}$ and poly(ionic liquid), as shown in Figure 2a. For better comparison, the FTIR spectrum of $\mathrm{Cu}_{3}(\mathrm{BTC})_{2}$ was plotted in the same figure. In both FTIR spectra, the characteristic absorption bands for benzene rings from $\mathrm{Cu}_{3}(\mathrm{BTC})_{2}$ can be clearly observed at 1625 and $1571 \mathrm{~cm}^{-1}$ [31]. The absorption bands at 1375 and $1280 \mathrm{~cm}^{-1}$ are assigned to the bending vibration of hydroxy groups of $\mathrm{COOH}$ and the stretching vibration of $\mathrm{C}-\mathrm{O}$, respectively. Compared to the spectrum of $\mathrm{Cu}_{3}(\mathrm{BTC})_{2}$, two new absorption bands appeared at 3126 and $1163 \mathrm{~cm}^{-1}$ in the FTIR spectrum of $\mathrm{Cu}_{3}(\mathrm{BTC})_{2}-\mathrm{PIL}^{-\mathrm{NH}_{2}}$ assigned to the stretching vibration of $=\mathrm{C}-\mathrm{H}$ and the stretching vibration of $\mathrm{C}-\mathrm{N}$ of the imidazole rings, indicating the successful complex formation [41]. Figure $2 \mathrm{~b}$ displays the XRD patterns of $\mathrm{Cu}_{3}(\mathrm{BTC})_{2}$ and $\mathrm{Cu}_{3}(\mathrm{BTC})_{2}-\mathrm{PIL}-\mathrm{NH}_{2}$. It can be seen that the diffraction peaks are very sharp for $\mathrm{Cu}_{3}(\mathrm{BTC})_{2}$, suggesting the great crystallinity. In addition, the position of diffraction peaks agrees well with those reported in the literature [31], indicating that crystallized $\mathrm{Cu}_{3}(\mathrm{BTC})_{2}$ was successfully synthesized. For $\mathrm{Cu}_{3}(\mathrm{BTC})_{2}-\mathrm{PIL}-\mathrm{NH}_{2}$, diffraction peaks were observed at the same angles of $\mathrm{Cu}_{3}(\mathrm{BTC})_{2}$ with decreased intensity and a new broad diffraction peak appeared at $2 \theta$ of $15-30^{\circ}$, revealing the existence of amorphous poly(ionic liquid)s and the partially destroyed crystalline structure of $\mathrm{Cu}_{3}(\mathrm{BTC})_{2}$.
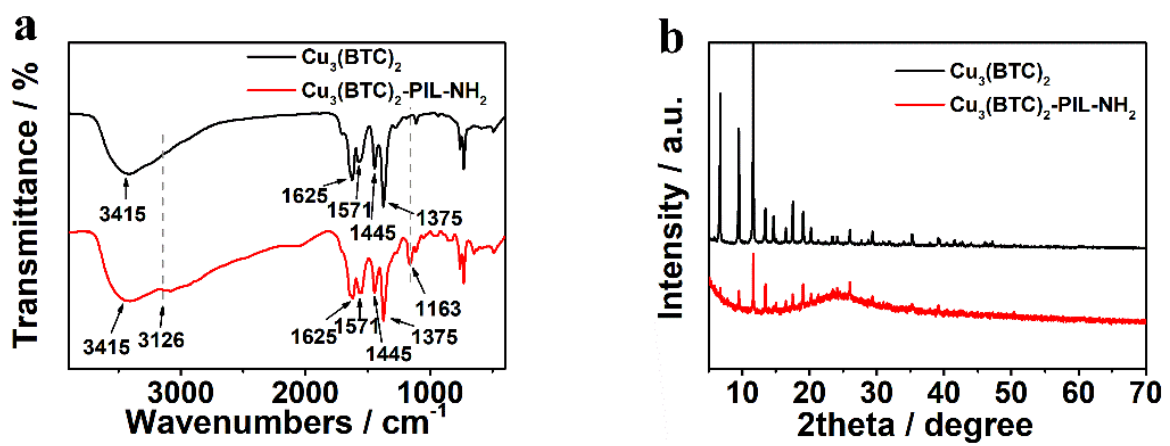

Figure 2. (a) FTIR spectra and (b) XRD patterns of $\mathrm{Cu}_{3}(\mathrm{BTC})_{2}$ and $\mathrm{Cu}_{3}(\mathrm{BTC})_{2}-\mathrm{PIL}-\mathrm{NH}_{2}$ as indicated in the figure. Dashed lines in the FTIR spectrum are a visual guide. 
Figure 3 shows XPS results of the synthesized $\mathrm{Cu}_{3}(\mathrm{BTC})_{2}-\mathrm{PIL}-\mathrm{NH}_{2}$ composite material. The full XPS survey (Figure 3a) clearly suggests the existence of atoms including $\mathrm{Cu}(781.2 \mathrm{eV}$ for $\mathrm{Cu} 2 \mathrm{p}$ ), $\mathrm{N}$ (400.8 eV for N 1s), O (531.3 eV for O 1s), C (285.6 eV for C 1s), and Br (67.7 eV for Br 3d), further confirming the formation of composite materials. To evaluate the bonding formation between $\mathrm{Cu}_{3}(\mathrm{BTC})_{2}$ and PIL-NH$H_{2}$, the high-resolution $\mathrm{N}$ 1s peak was deconvoluted, as shown in Figure $3 \mathrm{~b}$. It can be seen that $\mathrm{N}$ atoms in the composite material have four different bonding states with the binding energy centered at 398.28, 398.99, 400.09, and $401.03 \mathrm{eV}$. It has been reported that the peaks centered at 400.09 and $401.03 \mathrm{eV}$ corresponded to the $\mathrm{C}-\mathrm{N}$ and $\mathrm{C}=\mathrm{N}$ bonding on the imidazole rings of ionic liquid moieties [28]. The peaks at 398.28 and $398.99 \mathrm{eV}$ can be therefore assigned to amino groups. It is expected that two types of amino groups exist in the designed composite materials as free amino groups and the bonded amino groups with copper ions. Since the complexation of amino groups with transition metal ions can lead to reduced binding energy, the peak centered at 398.28 should correspond to amino groups interacted with copper ions and the peak centered at 398.99 is related to free amino groups in the composite material.
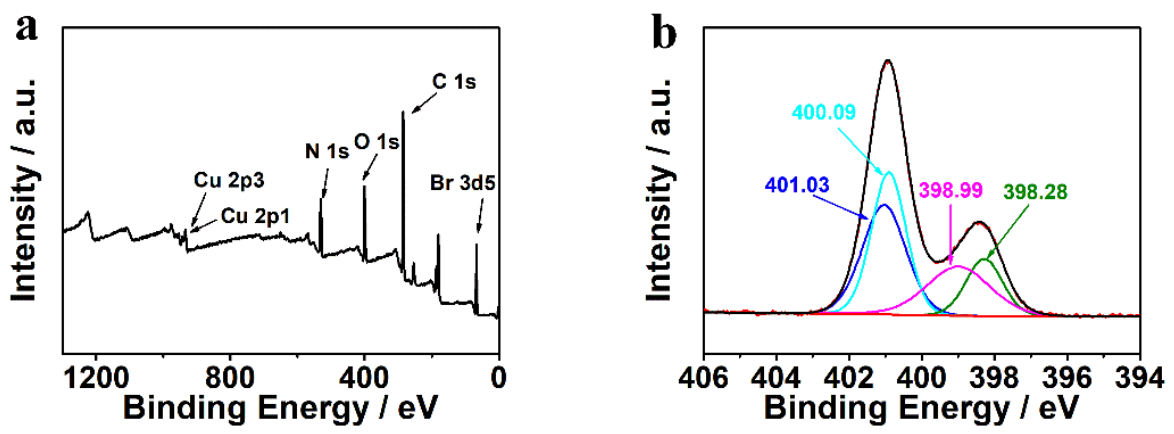

Figure 3. (a) Full XPS survey and (b) high-resolution $\mathrm{N}$ 1s XPS spectrum of $\mathrm{Cu}_{3}(\mathrm{BTC})_{2}-\mathrm{PIL}-\mathrm{NH}_{2}$. The deconvolution results of $\mathrm{N} 1$ s peak are also displayed in $(\mathbf{b})$.

The porous structure of sorbents has significant influence on their adsorption behavior of gaseous species. Nitrogen adsorption/desorption isotherms were therefore recorded to determine the porous structure of $\mathrm{Cu}_{3}(\mathrm{BTC})_{2}-\mathrm{PIL}-\mathrm{NH}_{2}$ and $\mathrm{Cu}_{3}(\mathrm{BTC})_{2}$, as shown in Figure 4. It is apparent that $\mathrm{Cu}_{3}(\mathrm{BTC})_{2}$ exhibited the typical Type I isotherms, suggesting the existence of micropores. With the grafting of PILs onto the sample's surface, the shape of the isotherm changed significantly, particularly under the low relative pressure, suggesting the significant decrease in numbers of micropores due to the blockage of surface-attached polymer chains. The derived porous parameters including surface area, pore volume, and average pore size are listed in Table 1. It can be seen that $\mathrm{Cu}_{3}(\mathrm{BTC})_{2}$ has a surface area of $1352 \mathrm{~cm}^{2} \cdot \mathrm{g}^{-1}$ with average pore size of $1.8 \mathrm{~nm}$ and pore volume of $0.61 \mathrm{~cm}^{3} \cdot \mathrm{g}^{-1}$. However, both surface area and pore volume dramatically decreased to $107 \mathrm{~m}^{2} \cdot \mathrm{g}^{-1}$ and $0.12 \mathrm{~cm}^{3} \cdot \mathrm{g}^{-1}$, respectively. This could be attributed to the tensive coverage of micropores on $\mathrm{Cu}_{3}(\mathrm{BTC})_{2}$ by the introduced polymer chains. The increased average pore diameter of the sample after complexation with PIL- $\mathrm{NH}_{2}$ is possibly related to slit pores or the formed pores due to accumulation of the PIL- $\mathrm{NH}_{2}$-modified particles.

Table 1. The derived porous parameters of $\mathrm{Cu}_{3}(\mathrm{BTC})_{2}$ and $\mathrm{Cu}_{3}(\mathrm{BTC})_{2}-\mathrm{PIL}-\mathrm{NH}_{2}$.

\begin{tabular}{cccc}
\hline Samples & Surface Area $\left(\mathbf{m}^{\mathbf{2}} \cdot \mathbf{g}^{\mathbf{- 1}}\right)$ & Pore Volume $\left(\mathbf{c m}^{\mathbf{3}} \cdot \mathbf{g}^{\mathbf{- 1}}\right)$ & Pore Size $(\mathbf{n m})$ \\
\hline $\mathrm{Cu}_{3}(\mathrm{BTC})_{2}$ & 1352 & 0.60 & 1.8 \\
$\mathrm{Cu}_{3}(\mathrm{BTC})_{2}-\mathrm{PIL}-\mathrm{NH}_{2}$ & 107 & 0.12 & 4.5 \\
\hline
\end{tabular}




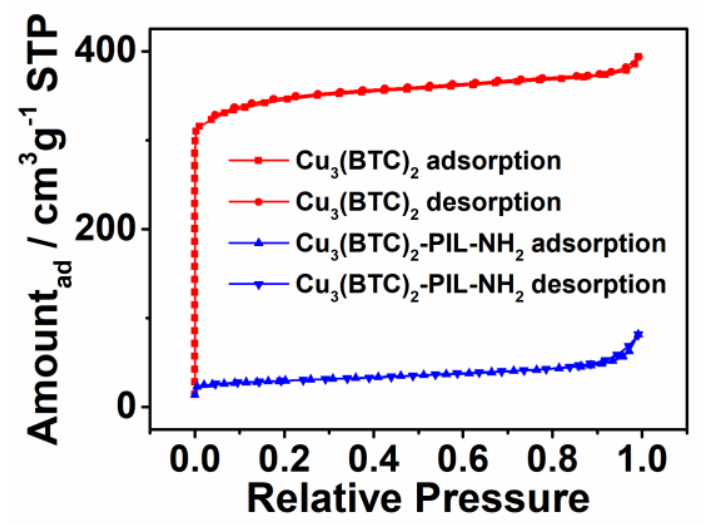

Figure 4. Nitrogen adsorption-desorption isotherms for $\mathrm{Cu}_{3}(\mathrm{BTC})_{2}$ and $\mathrm{Cu}_{3}(\mathrm{BTC})_{2}-\mathrm{PIL}-\mathrm{NH}_{2}$.

Since $\mathrm{CO}_{2}$ adsorption was investigated using the temperature-programmed desorption (TPD) technique, the thermal stability of sorbents is one essential parameter to be achieved. Figure 5 shows the TG and DTG curves of $\mathrm{Cu}_{3}(\mathrm{BTC})_{2}$ and $\mathrm{Cu}_{3}(\mathrm{BTC})_{2}-\mathrm{PIL}-\mathrm{NH}_{2}$. It can be seen that both samples have apparent weight losses under temperatures below $120^{\circ} \mathrm{C}$ and under temperatures above $275^{\circ} \mathrm{C}$, corresponding to the release of the physically adsorbed water molecules and the decomposition of organic parts (BTC and PIL), respectively. Compared with $\mathrm{Cu}_{3}(\mathrm{BTC})_{2}, \mathrm{Cu}_{3}(\mathrm{BTC})_{2}-\mathrm{PIL}-\mathrm{NH}_{2}$ exhibits one additional weight loss region between 210 and $275^{\circ} \mathrm{C}$, possibly attributed to the release of structured water molecules that are interacted with $\mathrm{N}$ atoms in PIL through hydrogen bonding. It can be thus concluded that the synthesized $\mathrm{Cu}_{3}(\mathrm{BTC})_{2}-\mathrm{PIL}-\mathrm{NH}_{2}$ is thermally stable at temperatures below $200{ }^{\circ} \mathrm{C}$ and the operational temperature for TPD measurements can be set to $200{ }^{\circ} \mathrm{C}$.
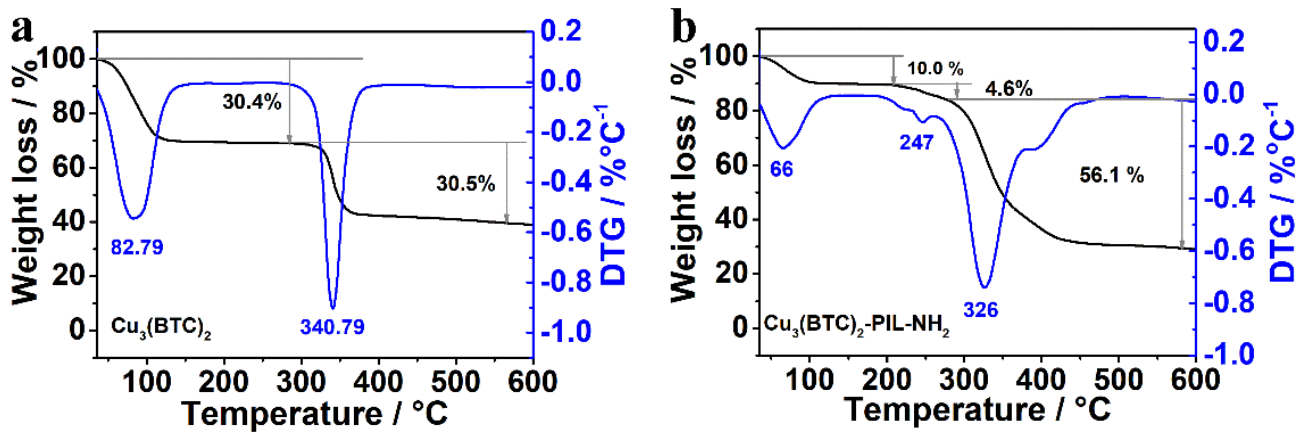

Figure 5. (a) TG (black) and DTG (blue) curves of $\mathrm{Cu}_{3}(\mathrm{BTC})_{2}$. (b) TG (black) and DTG (blue) curves of $\mathrm{Cu}_{3}(\mathrm{BTC})_{2}-\mathrm{PIL}-\mathrm{NH}_{2}$. The corresponding weight loss values are listed in the figure.

The $\mathrm{CO}_{2}$ adsorption behavior was determined by desorption (TPD technique) under the temperature range of 25 to $200{ }^{\circ} \mathrm{C}$ of pre-adsorbed $\mathrm{CO}_{2}$ molecules in the samples at $25{ }^{\circ} \mathrm{C}$ under $\mathrm{CO}_{2}$ pressure of 0.2 bar for $2 \mathrm{~h}$. The TPD response curves for $\mathrm{Cu}_{3}(\mathrm{BTC})_{2}$ and $\mathrm{Cu}_{3}(\mathrm{BTC})_{2}-\mathrm{PIL}-\mathrm{NH}_{2}$ are plotted in Figure 6. It is evident that only one desorption peak at about $95{ }^{\circ} \mathrm{C}$ was observed for $\mathrm{Cu}_{3}(\mathrm{BTC})_{2}$. The corresponding calculated $\mathrm{CO}_{2}$ adsorption capacity is about $3.09 \mathrm{~cm}^{3} \cdot \mathrm{g}^{-1}$. The observed desorption peak can be therefore assigned to the desorption of physically adsorbed $\mathrm{CO}_{2}$ molecules and the adsorbed $\mathrm{CO}_{2}$ molecules through weak interaction with copper ions in $\mathrm{Cu}_{3}(\mathrm{BTC})_{2}$ [31]. For $\mathrm{Cu}_{3}(\mathrm{BTC})_{2}-\mathrm{PIL}-\mathrm{NH}_{2}$, there are two desorption peaks at about 96 and $200{ }^{\circ} \mathrm{C}$, respectively. Similar to that for $\mathrm{Cu}_{3}(\mathrm{BTC})_{2}$, the desorption peak at $96^{\circ} \mathrm{C}$ can be attributed to the release of physically adsorbed $\mathrm{CO}_{2}$ molecules. The physically adsorbed amount is about $2.24 \mathrm{~cm}^{3} \cdot \mathrm{g}^{-1}$, smaller than that of $\mathrm{Cu}_{3}(\mathrm{BTC})_{2}$ due to the decreased surface area. It is thus hypothesized that the desorption at temperatures above $100{ }^{\circ} \mathrm{C}$ could be attributed to the chemical adsorption of $\mathrm{CO}_{2}$ molecules induced by the presence of PIL- $\mathrm{NH}_{2}$ chains as the release of chemically adsorbed $\mathrm{CO}_{2}$ molecules requires more energy. Since both amino groups and 2-position carbon atoms in the imidazole ring can be chemically interacted with 
$\mathrm{CO}_{2}$ molecules $[36,37,41]$, the $\mathrm{Cu}_{3}(\mathrm{BTC})_{2}$-PIL- $\mathrm{NH}_{2}$ exhibited a considerably large chemical adsorption capacity of about $17.3 \mathrm{~cm}^{3} \cdot \mathrm{g}^{-1}$.

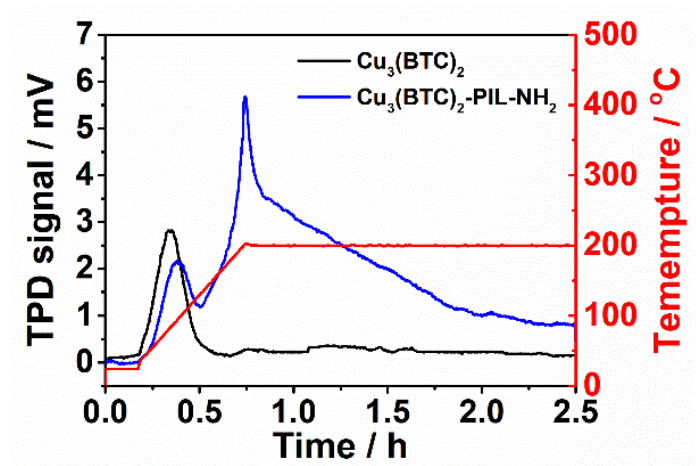

Figure 6. $\mathrm{CO}_{2}$ TPD response curves for $\mathrm{Cu}_{3}(\mathrm{BTC})_{2}$ and $\mathrm{Cu}_{3}(\mathrm{BTC})_{2}-\mathrm{PIL}-\mathrm{NH}_{2}$. Red line in the figure refers to the temperature profile for desorption.

\section{Discussion}

To validate the hypothesis on the physisorption and chemisorption of $\mathrm{CO}_{2}$ using $\mathrm{Cu}_{3}(\mathrm{BTC})_{2}-\mathrm{PIL}-\mathrm{NH}_{2}$ as sorbent, the adsorption of $\mathrm{CO}_{2}$ at different temperatures was performed and the same TPD process was applied. The $\mathrm{CO}_{2}$ TPD response curves are displayed in Figure 7. In general, the physisorption capacity of gaseous species decreased with the increase in temperature due to the existing equilibrium of adsorption and desorption, whereas the chemisorption capacity increased with the increase in temperature because of the enhanced reaction kinetics $[11,13,21]$. It is evident that the peak intensity at temperature of about $95^{\circ} \mathrm{C}$ decreased and the peak intensity at about $200{ }^{\circ} \mathrm{C}$ increased while the adsorption temperature increased from 10 to $40{ }^{\circ} \mathrm{C}$. The corresponding desorbed amount at $95{ }^{\circ} \mathrm{C}$ calculated from TPD curves decreased from 3.4 to $1.4 \mathrm{~cm}^{3} \cdot \mathrm{g}^{-1}$ with the increase in adsorption temperature from 10 to $40^{\circ} \mathrm{C}$, suggesting that the desorption at $95^{\circ} \mathrm{C}$ resulted from the physically adsorbed $\mathrm{CO}_{2}$. In contrast, the desorbed amount at $200^{\circ} \mathrm{C}$ increased from 14.6 to $17.6 \mathrm{~cm}^{3} \cdot \mathrm{g}^{-1}$ with the increase in adsorption temperature from 10 to $40^{\circ} \mathrm{C}$, indicating that the desorption at $200{ }^{\circ} \mathrm{C}$ resulted from the chemisorption of $\mathrm{CO}_{2}$ molecules through the interaction between $\mathrm{CO}_{2}$ molecules with amino groups and 2-position carbon atoms of imidazolium-type poly(ionic liquid)s. It should be mentioned that the chemically adsorbed amount at $40^{\circ} \mathrm{C}$ is only slightly higher than that at $25^{\circ} \mathrm{C}$. The total $\mathrm{CO}_{2}$ adsorption capacity at $25^{\circ} \mathrm{C}\left(19.5 \mathrm{~cm}^{3} \cdot \mathrm{g}^{-1}\right)$ is higher than that at $40{ }^{\circ} \mathrm{C}$ $\left(19.0 \mathrm{~cm}^{3} \cdot \mathrm{g}^{-1}\right)$ due to the good physical adsorption. It should also be mentioned that the total $\mathrm{CO}_{2}$ adsorption capacity of $\mathrm{Cu}_{3}(\mathrm{BTC})_{2}-\mathrm{PIL}-\mathrm{NH}_{2}$ derived from the TPD technique is still quite low for practical applications due to the possibly slow adsorption kinetics and the limitation of the apparatus which cannot be applied at high pressure. It is expected that the $\mathrm{CO}_{2}$ adsorption capacity can be greatly improved with the increase in operational pressures with which physical adsorption of $\mathrm{CO}_{2}$ on porous materials can be significantly enhanced. 


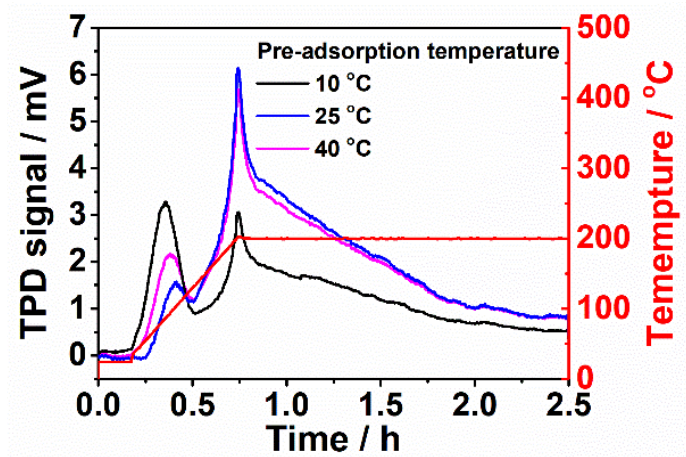

Figure 7. $\mathrm{CO}_{2}$ TPD response curves of $\mathrm{Cu}_{3}(\mathrm{BTC})_{2}-\mathrm{PIL}-\mathrm{NH}_{2}$ for pre-adsorption of $\mathrm{CO}_{2}$ at different temperatures. Red line in the figure refers to the temperature profile for desorption.

\section{Conclusions}

In summary, anamine-functionalized imidazolium-type poly(ionic liquid)-modified metal organic framework was synthesized as sorbent for carbon dioxide adsorption via complexation of amino groups on polymer chains and metal ions. After modification with functionalized poly(ionic liquid) chains, the surface area of the metal organic framework reduced significantly, leading to a decreased physical adsorption capacity of carbon dioxide molecules. However, the chemical adsorption through interaction of amino groups and 2-position carbon atoms on the imidazolium rings with carbon dioxide dominates the total adsorption capacity under the relatively low carbon dioxide pressure. Moreover, the physisorption and chemisorption of carbon dioxide on the synthesized composite sorbents can be easily identified using the temperature-programmed desorption technique. The results in this work demonstrate that the modification of porous materials with amine-functionalized imidazolium-type poly(ionic liquid)s can be a promising approach in the design and synthesis of model sorbents for efficient carbon dioxide adsorption by improving the physical adsorption kinetics under high pressure.

Author Contributions: Conceptualization, S.P. and H.Z.; methodology, G.Y., J.Y., and K.S.; data curation, K.S.; writing-original draft preparation, G.Y. and J.Y.; writing—review and editing, H.Z.; supervision, S.P. and H.Z. All authors have read and agreed to the published version of the manuscript.

Funding: This research was funded by the Natural Science Foundation of China, grant number 21878239.

Conflicts of Interest: The authors declare no conflict of interest.

\section{References}

1. Stocker, T.F.; Qin, D.; Plattner, G.K.; Tignor, M.; Allen, S.K.; Boschung, J.; Nauels, A.; Xia, Y.; Bex, V.; Midgley, P.M. Climate change 2013: The physical science basis. In Intergovernmental Panel on Climate Change, Working Group I Contribution to the IPCC Fifth Assessment Report (AR5); Cambridge University Press: New York, NY, USA, 2013.

2. Knudsen, J.N.; Jensen, J.N.; Vilhelmsen, P.J.; Biede, O. Experience with $\mathrm{CO}_{2}$ capture from coal flue gas in pilot-scale: Testing of different amine solvents. Energy Procedia 2009, 1, 783-790. [CrossRef]

3. White, C.M.; Strazisar, B.R.; Granite, E.J.; Hoffmann, J.S.; Pennline, H.W. Separation and capture of $\mathrm{CO}_{2}$ from large stationary sources and sequestration in geological formations-Coalbeds and deep saline aquifers. J. Air Waste Manag. Assoc. 2003, 53, 645-715. [CrossRef]

4. Li, L.; Zhao, N.; Wei, W.; Sun, Y.H. A review of research progress on $\mathrm{CO}_{2}$ capture, storage, and utilization in Chinese Academy of Sciences. Fuel 2013, 108, 112-130. [CrossRef]

5. MacDowell, N.; Florin, N.; Buchard, A.; Hallett, J.; Galindo, A.; Jackson, G.; Adjiman, C.S.; Williams, C.K.; Shah, N.; Fennell, P. An overview of $\mathrm{CO}_{2}$ capture technologies. Energy Environ. Sci. 2010, 3, 1645-1669. [CrossRef]

6. Dutcher, B.; Fan, M.; Russell, A.G. Amine-based $\mathrm{CO}_{2}$ capture technology development from the beginning of 2013-a review. ACS Appl. Mater. Interfaces 2015, 7, 2137-2148. [CrossRef] 
7. Sharma, S.D.; Azzi, M. A critical review of existing strategies for emission control in the monoethanolamine-based carbon capture process and some recommendations for improved strategies. Fuel 2014, 212, 178-188. [CrossRef]

8. Rochelle, G.T. Amine scrubbing for $\mathrm{CO}_{2}$ capture. Science 2009, 325, 1652-1654. [CrossRef]

9. Abdelhamid, A.; Heydari-Gorji, A.; Yang, Y. $\mathrm{CO}_{2}$-induced degradation of amine-containing adsorbents: Reaction products and pathways. J. Am. Chem. Soc. 2012, 134, 13834-13842.

10. Dahl, K.H.; Helgesen, L. Safety assessment of emissions from amine-based post combustion $\mathrm{CO}_{2}$-capture. Toxicol. Lett. 2012, 211, S122-S123. [CrossRef]

11. Pera-Titus, M. Porous inorganic membranes for $\mathrm{CO}_{2}$ capture: Present and prospects. Chem. Rev. 2014, 114, 1413-1492. [CrossRef]

12. Knoefel, C.; Martin, C.; Hornebecq, V.; Llewellyn, P.L. Study of carbon dioxide adsorption on mesoporous aminopropylsilane-functionalized silica and titania combining microcalorimetry and in situ infrared spectroscopy. J. Phys. Chem. C 2009, 113, 12726-12734. [CrossRef]

13. Vaidhyanathan, R.; Iremonger, S.S.; Shimizu, G.K.H.; Boyd, P.G.; Alavi, S.; Woo, T.K. Direct observation and quantification of $\mathrm{CO}_{2}$ binding within an amine-functionalized nanoporous solid. Science 2010, 330, 650-653. [CrossRef]

14. Qi, G.; Wang, Y.; Estevez, L.; Duan, X.; Anako, N.; Park, A.H.A.; Li, W.; Jones, C.W.; Giannelis, E.P. High efficiency nanocomposite sorbents for $\mathrm{CO}_{2}$ capture based on amine-functionalized mesoporous capsules. Energy Environ. Sci. 2011, 4, 444-452. [CrossRef]

15. Sculley, J.P.; Zhou, H.C. Enhancing amine-supported materials for ambient air capture. Angew. Chem. Int. Ed. 2012, 51, 12660-12661. [CrossRef]

16. Aquino, C.C.; Richner, G.; Kimling, M.C.; Chen, D.; Puxty, G.; Feron, P.H.M.; Caruso, R.A. Amine-functionalized titania-based porous structures for carbon dioxide postcombustion capture. J. Phys. Chem. C 2013, 117, 9747-9757. [CrossRef]

17. Bali, S.; Leisen, J.; Foo, G.S.; Sievers, C.; Jones, C.W. Aminosilanes grafted to basic alumina as $\mathrm{CO}_{2}$ adsorbents-role of grafting conditions on $\mathrm{CO}_{2}$ adsorption properties. ChemSusChem 2014, 7, 3145-3156. [CrossRef]

18. Linneen, A.N.; Pfeffer, R.; Lin, Y.S. $\mathrm{CO}_{2}$ adsorption performance for amine grafted particulate silica aerogels. Chem. Eng. J. 2014, 254, 190-197. [CrossRef]

19. Liu, Q.; Shi, J.; Wang, Q.; Tao, M.; He, Y.; Shi, Y. Carbon dioxide capture with polyethylenimine-functionalized industrial-grade multiwalled carbon nanotubes. Ind. Eng. Chem. Res. 2014, 53, 17468-17475. [CrossRef]

20. Prenzel, T.; Wilhelm, M.; Rezwan, K. Tailoring amine functionalized hybrid ceramics to control $\mathrm{CO}_{2}$ adsorption. Chem. Eng. J. 2014, 235, 198-206. [CrossRef]

21. Millward, A.R.; Yaghi, O.M. Metal-organic-framework with exceptionally high capacity for storage of carbon dioxide at room temperature. J. Am. Chem. Soc. 2005, 127, 17998-17999. [CrossRef]

22. Furukawa, H.; Ko, N.; Go, Y.N.; Aratani, N.; Choi, S.B.; Choi, E.; Yazaydin, O.; Snurr, O.Q.; O’Keeffe, M.; Kim, J.; et al. Ultrahigh porosity in metal-organic- frameworks. Science 2010, 329, 424-428. [CrossRef]

23. Wang, S.; Yao, W.; Lin, J.; Ding, Z.; Wang, X. Cobalt imidazolate metal-organic frameworks photosplit $\mathrm{CO}_{2}$ under mild reaction conditions. Angew. Chem. Int. Ed. 2014, 53, 1034-1038. [CrossRef]

24. Fracaroli, A.M.; Furukawa, H.; Suzuki, M.; Dodd, M.; Okajima, S.; Gandara, F.; Reimer, J.A.; Yaghi, O.M. Metal-organic frameworks with precisely designed interior for carbon dioxide capture in the presence of water. J. Am. Chem. Soc. 2014, 136, 8863-8866. [CrossRef]

25. Lai, L.S.; Yeong, Y.F.; Ani, A.C.; Lau, K.K.; Shariff, A.M. Effect of synthesis parameters on the formation of zeolitic imidazolate framework 8 (ZIF-8) nanoparticles for $\mathrm{CO}_{2}$ adsorption. Part. Sci. Technol. 2014, 32, 520-528. [CrossRef]

26. Martinez, F.; Sanz, R.; Orcajo, G.; Briones, D.; Yanguez, V. Amino-impregnated MOF materials for $\mathrm{CO}_{2}$ capture at post-combustion conditions. Chem. Eng. Sci. 2016, 142, 55-61. [CrossRef]

27. Qian, X.; Ren, Q.; Wu, X.; Sun, J.; Wu, H.; Lei, J. Enhanced water stability in Zn-doped zeolitic imidazolate framework (ZIF) for $\mathrm{CO}_{2}$ capture applications. ChemsitrySelect 2018, 3, 657-661. [CrossRef]

28. Song, X.; Yu, J.; Wei, M.; Li, R.; Pan, X.; Yang, G.; Tang, H. Ionic liquids-functionalized zeolitic imidazolate framework for carbon dioxide adsorption. Materials 2019, 12, 2361. [CrossRef]

29. Dhakshinamoorthy, I.; Li, Z.; Garcia, H. Catalysis and photocatalysis by metal organic frameworks. Chem. Soc. Rev. 2018, 47, 8134-8172. [CrossRef] 
30. Dhakshinamoorthy, I.; Asiri, A.M.; Garcia, H. 2D Metal-Organic Frameworks as Multifunctional Materials in Heterogeneous Catalysis and Electro/Photocatalysis. Adv. Mater. 2019, 31, 201900617. [CrossRef]

31. Thi, T.V.N.; Luu, C.L.; Hoang, T.C.; Nguyen, T.; Bui, T.H.; Nguyen, P.H.D.; Thi, T.P.P. Synthesis of MOF-199 and application to $\mathrm{CO}_{2}$ adsorption. Adv. Nat. Sci. Nanosci. Nanotechnol. 2013, 4, 035016.

32. Demessence, A.; D'Alessandro, D.M.; Foo, M.L.; Long, J.R. Strong $\mathrm{CO}_{2}$ binding in a water-stable, triazolate-bridged metal-organic framework functionalized with ethylenediamine. J. Am. Chem. Soc. 2009, 131, 8784-8786. [CrossRef]

33. Finotello, A.; Bara, J.E.; Camper, D.; Boble, R.D. Room-temperature ionic liquids: Temperature dependence of gas solubility. Ind. Eng. Chem. Res. 2008, 47, 3453-3459. [CrossRef]

34. Condemarin, R.; Scovazzo, P. Gas permeabilities, solubilities, diffusivities, and diffusivity correlations for ammonium-based room temperature ionic liquids with comparison to imidazolium and phosphonium RTIL data. Chem. Eng. J. 2009, 147, 51-57. [CrossRef]

35. Shannon, M.S.; Tedstone, J.M.; Danielsen, S.P.O.; Hindman, M.S.; Irvin, A.C.; Bara, J.E. Free volume as the basis of gas solubility and selectivity in imidazolium-based ionic liquids. Ind. Eng. Chem. Res. 2012, 51, 5565-5576. [CrossRef]

36. Gurau, G.; Rodriguez, H.; Kelley, S.P.; Janiczek, P.; Kalb, R.S.; Rogers, R.D. Demonstration of chemisorption of carbon dioxide in 1,3-dialkylimidazolium acetate ionic liquids. Angew. Chem. Int. Ed. 2011, 50, 12024-12026. [CrossRef]

37. Seo, S.; DeSilva, M.A.; Brennecke, J.F. Physical properties and $\mathrm{CO}_{2}$ reaction pathway of 1-ethyl-3-methylimidazolium ionic liquids with aprotic heterocyclic anions. J. Phys. Chem. B 2014, 118, 14870-14879. [CrossRef]

38. Gutowski, K.E.; Maginn, E.J. Amine-functionalized task-specific ionic liquids: A mechanistic explanation for the dramatic increase in viscosity upon complexation with $\mathrm{CO}_{2}$ from molecular simulation. J. Am. Chem. Soc. 2008, 130, 14690-14704. [CrossRef]

39. Tang, J.; Tang, H.; Sun, W.; Radosz, M.; Shen, Y. Poly(ionic liquid)s as new materials for $\mathrm{CO}_{2}$ absorption. J. Polym. Sci. A Polym. Chem. 2005, 43, 5477-5489. [CrossRef]

40. Magalhaes, T.O.; Aquino, A.S.; Dalla Vecchia, F.; Bernard, F.L.; Seferin, M.; Menezes, S.C.; Ligabue, R.; Einloft, S. Syntheses and characterization of new poly(ionic liquid)s designed for $\mathrm{CO}_{2}$ capture. RSC Adv. 2014, 4, 18164-18170. [CrossRef]

41. Yuan, J.; Fan, M.; Zhang, F.; Xu, Y.; Tang, H.; Huang, C.; Zhang, H. Amine-functionalized poly(ionic liquid) brushes for carbon dioxide adsorption. Chem. Eng. J. 2017, 316, 903-910. [CrossRef]

42. Fang, W.; Luo, Z.; Jiang, J. $\mathrm{CO}_{2}$ capture in poly(ionic liquid) membranes: Atomistic insight into the role of anions. Phys. Chem. Chem. Phys. 2013, 15, 651-658. [CrossRef]

43. Li, N.; Qu, R.; Han, X.; Lin, W.; Zhang, H.; Zhang, Z.J. The counterion effect of imidazolium-type poly(ionic liquid) brushes on carbon dioxide adsorption. ChemPlusChem 2019, 84, 281-288. [CrossRef] 